\title{
Trends in long-term cardiovascular mortality and morbidity in men and women with heart failure of ischemic versus non-ischemic aetiology in Western Australia between 1990 and 2005
}

\author{
Tiew-Hwa Katherine Teng a,*, Joseph Hung ${ }^{\mathrm{b}}$, Matthew Knuiman ${ }^{\mathrm{a}}$, Simon Stewart ${ }^{\mathrm{c}}$, Leonard Arnolda ${ }^{\mathrm{d}}$, \\ Ian Jacobs ${ }^{\mathrm{e}}$, Michael Hobbs ${ }^{\mathrm{a}}$, Frank Sanfilippo ${ }^{\mathrm{a}}$, Elizabeth Geelhoed ${ }^{\mathrm{a}}$, Judith Finn ${ }^{\mathrm{e}}$ \\ a School of Population Health (M431), University of Western Australia, Perth, Western Australia, Australia \\ b School of Medicine and Pharmacology (M503), Sir Charles Gairdner Hospital Unit, University of Western Australia, Perth, Western Australia, Australia \\ c Preventative Health, Baker IDI Heart and Diabetes Institute, Melbourne, Victoria, Australia \\ d The Canberra Hospital, Australian National University Medical School, Canberra, Australian Capital Territory, Australia \\ e Discipline of Emergency Medicine, University of Western Australia, Perth, Western Australia, Australia
}

\section{A R T I C L E I N F O}

\section{Article history:}

Received 22 December 2010

Received in revised form 18 January 2011

Accepted 23 January 2011

Available online $\mathrm{xxxx}$

\section{Keywords:}

Heart failure

Survival

Gender

Hospitalization

\begin{abstract}
A B S T R A C T
Background: It is uncertain if improvements in long-term cardiovascular (CV) mortality have occurred in both men and women with ischemic and non-ischemic forms of heart failure (HF).

Methods: The Western Australia Hospital Morbidity Database was used to identify all index (first-ever) hospitalizations for HF between 1990 and 2005. Patients were followed until death attributed to cardiovascular causes or censored on December 31, 2006 to determine 5-year survival. Cox proportional hazards models were used to compare the adjusted mortality hazard ratio (HR) during the study follow-up (4-year periods).

Results: A total of 21,507 patients (mean age 73.9 years, $49.1 \%$ women) were identified. Women were significantly older than men, and less likely to have ischemic HF (38.8\% versus 46.1\%). Over the period, age-standardized incidence of first HF hospitalization declined but with the least decline in women with non-ischemic HF $(-13.3 \%)$ compared to other subgroups. Risk-adjusted 5-year CV mortality declined over the study period, with HR 0.64 (95\% CI 0.60-0.68) for patients admitted in 1998-2001 compared to 1990-1993, with significant improvement in both forms of $\mathrm{HF}$, and in both sexes and across age groups. However, overall total HF hospitalizations increased $(+26.7 \%)$ over the period, particularly for non-ischemic HF $(+43.7 \%)$, of which elderly women formed the predominant group.

Conclusions: Risk-adjusted long-term survival improved similarly in men and women, including the elderly, with ischemic and non-ischemic forms of HF during 1990-2005 in Western Australia. However, there was a growing burden of HF hospitalizations particularly for HF of non-ischemic aetiology.
\end{abstract}

(C) 2011 Elsevier Ireland Ltd. All rights reserved.

\section{Introduction}

Heart failure (HF) is a major public health problem [1]. Although population-based studies have suggested an improved prognosis for HF since the late 1980s [2-4] survival in HF remains poor, with a 5-year all-cause mortality of $60 \%$ or more after HF hospitalization [5-7]. The advent of proven HF treatments in the 1990s, including angiotensinconverting enzyme (ACE) inhibitors, beta-blockers, and aldosterone antagonists, has been shown to improve survival in patients with HF related to left ventricular systolic dysfunction [8-10]. Similarly, advances in evidence-based treatments including revascularization procedures in ischemic heart disease (IHD) have the potential to

* Corresponding author. School of Population Health, M431, University of Western Australia, 35, Stirling Highway, Australia. Tel.: +61 86388 7830; fax: +61 864881188. E-mail address: kteng@meddent.uwa.edu.au (T.-H.K. Teng). prolong survival in patients with IHD at high risk of developing HF [11-13]. Conversely, there is a paucity of evidence-based treatments for HF with preserved systolic function (PSF) [14].

In contrast to the usual patients included in clinical trials, population-based studies have shown that HF is predominantly a condition of older age and as much as half of the patients hospitalized with HF have PSF, which comprises women as a predominant group [14-16]. Additionally, gender differences in the genesis and treatment of HF have been reported, with men being more affected by IHD and less by hypertension than women, and with less aggressive procedurebased treatments reported in women [15-17]. Population-based studies are important as they reflect the full spectrum of patients hospitalized with HF, and can assess the impact of changing HF management on long-term survival in the total population.

We have previously reported improved mortality at 30-days and 1-year in patients after index hospitalization for HF in Western 
Australia (WA) over the period 1990 to 2005, coincident with a growing uptake of evidence-based HF treatments $[17,18]$. The present study extends our investigation, first, to examine trends in long-term (5-year) cardiovascular (CV) cause-specific mortality of patients after index hospitalization for HF; second, to compare trends in long-term CV mortality and hospitalization of patients with ischemic and nonischemic forms of HF and third, to examine differences in gender and age-specific trends in these patients.

\section{Methodology}

\subsection{Study population}

The WA Hospital Morbidity Database (HMD) records principal and secondary discharge diagnoses in 21 fields for all public and private hospitalized patients in WA since the 1970 s, and is routinely linked to other health data such as the death register [19]. The WA HMD was used to identify patients with an index non-elective hospitalization for HF between 1990 and 2005, defined as no prior HF admissions in WA in the previous 10 years [18]. Patients were followed until death attributed to cardiovascular causes or censored on December 31,2006. The analyses were restricted to WA residents aged $\geq 20$ years at time of the index HF hospitalization.

\subsection{Identification of heart failure}

HF was identified using International Classification of Diseases, ICD9 and ICD10 diagnostic codes. For the first-listed (principal) diagnosis of HF, ICD9 codes were 428x, 402.01, 402.11, 402.91, 404.1, 404.3, 425x, 518.4, 514, 391.8 and 398.91; and ICD10 codes were I50x, I11.0, I13.0, I13.2, I42x, J81, I01.8 and I020. We also identified index cases of HF as a secondary diagnosis who had a principal diagnosis of a cardiovascular condition excluding acute myocardial infarction (AMI) (ICD9 codes $411 \mathrm{x}-427 \mathrm{x}$ and 429x and ICD10 codes I24X-I48X and I51X) [18]. Most index HF cases (72.7\%) coded HF as a principal diagnosis. The majority of cases with HF as a secondary diagnosis had a principal diagnosis of IHD (55.5\%) or atrial fibrillation (AF) (34.6\%).

In a random sample of 1006 patients in the WA HMD, a principal diagnosis of HF had a positive predictive value of $92.4 \%$ when compared to the HF Boston 'definite' score criteria and $98.8 \%$ for a combined 'possible' and 'definite' HF Boston score [20].

\subsection{Definition of comorbidities}

Comorbidities were identified from the ICD principal or secondary diagnosis codes recorded on any HMD record (with up to 21 non-specific diagnosis fields and 11 procedural fields) within 5 years prior or on index admission. The following conditions/ procedures were identified: any IHD (including AMI and angina), AF, hypertension, diabetes, renal failure, chronic obstructive pulmonary disease (COPD), peripheral vascular disease (PVD), cerebrovascular disease, rheumatic heart disease, cardiomyopathy and coronary artery revascularization procedures (CARPs) including percutaneous transluminal coronary angioplasty (PTCA) and coronary artery bypass graft surgery (CABG). A Charlson Comorbidity Index (CCI), as a weighted summary score, was also calculated for each person [21]. The ischemic subgroup of HF was identified as patients with a prior or coexistent history of any IHD including CARPs.

\subsection{Definition of cardiovascular (CV) mortality}

$\mathrm{CV}$ cause-specific mortality was considered as the underlying cause of death if the cause of death was assigned an International Classification of Diseases, ICD9 code (390 to 459 ) or ICD10 code (I00 to I99), as defined by the Australian Bureau of Statistics [22]. $\mathrm{CV}$ mortality rather than all-cause mortality was examined because of competing causes of death particularly among older individuals in a HF cohort.

\subsection{Statistical analysis}

Incident HF cases were divided into four equal calendar periods of 1990-1993 [base period], 1994-1997, 1998-2001, and 2002-2005, for comparison purposes. Survival times were calculated from the index HF admission to death (due to cardiovascular causes) within 5 years or until censored at December 31, 2006. We included all index HF cases between 1990 and 2001 for survival analysis to 5 years.

Categorical variables were presented as proportions and continuous variables as means \pm standard deviation or median and interquartile range. Pearson's chi-square test was used to test for differences in categorical variables and ANOVA, $t$-test or nonparametric Mann-Whitney test for continuous variables. Trends (in proportions) were assessed using the Cochran-Armitage trend test. The age-standardized (index HF) rate per 100,000 population was calculated by direct standardization using the Australian 2001 population age distribution [23]. Poisson regression was used to assess trends in HF incidence rates.

Cox proportional hazards models were used to examine predictors of CV death within 5 years, with hazard ratios (HRs) and 95\% confidence intervals (CIs) reported, and $\mathrm{p}<0.05$ considered significant. For each univariate regression model, predictors with $\mathrm{p}$ values $<0.15$ were included in the multivariable models. Models included age, gender, calendar period, individual comorbidities, CCI and CARPs. CARPs performed prior to and concomitantly with the index HF admission were examined as separate covariates as they might affect subsequent mortality risk differently. The weighted summary score of $\mathrm{CCI}$ and individual comorbid conditions were included in the multivariable models as the inclusion of individual comorbidities as well as CCI provided better risk adjustment than the use of the $\mathrm{CCI}$ alone.

The statistical analyses were done with SAS 9.1 and STATA 10. Interactions were found between age and year of admission $(p<0.001)$, sex and ischemic $\operatorname{HF}(p=0.06)$, and year of admission and ischemic $\mathrm{HF}(\mathrm{p}<0.001)$. Hence, ischemic and non-ischemic analyses, stratified by age and sex, are presented. The median age ( 75 years) was used for age stratification.

\subsection{Ethics approvals}

Ethics approval was obtained from the Human Research Ethics Committees of the University of Western Australia and WA Department of Health.

\section{Results}

\subsection{Population characteristics}

Over the study period, 21,507 index HF cases (mean age 73.9 years, $49.1 \%$ women) were identified. Prior or coexistent IHD was present in $42.5 \%$ of cases (Table 1 ). Women were more likely to have non-ischemic HF and were on average 5 years older than men at first hospitalization irrespective of aetiology (Table 1). Both HF subgroups showed a significant increase in mean age over the study period, primarily in men with ischemic HF (from 71.5 years to 72.9 years, $p=0.001$ ) and in women with non-ischemic HF (from 75.3 years to 76.3 years, $p=0.018$ ).

In addition to IHD (including prior MI), common comorbid conditions recorded were: hypertension (47.4\%), AF (34.4\%), diabetes (23.7\%), COPD (25.4\%), renal failure (11.9\%), PVD (14.2\%), and cerebrovascular disease (16.3\%) (Table 1). Hypertension was more prevalent in women than men (52.2\% versus $42.9 \%)$, while IHD was more prevalent in men ( $55.2 \%$ versus $44.8 \%$ ). As expected, comorbidities were more prevalent in older patients but notably diabetes was more prevalent in those aged $<75$ years with either form of $\mathrm{HF}$ (Table 1 ).

\subsection{Trend in HF hospitalization}

The age-standardized rate of index HF progressively declined over the study period for both ischemic and non-ischemic forms of HF and for both sexes. Comparing the last to first period, the greatest relative decline $(-41.3 \%)$ was seen in women with ischemic HF (from 44.5 to 26.1 per 100,000 population). In contrast, women with non-ischemic HF had the smallest decline (from 62.2 to 53.9 per 100,000 population, a relative change of $-13.3 \%$ ). Similar trends and magnitude of relative change $(-21.3 \%$ and $-20.8 \%)$ were seen for men with ischemic and non-ischemic HF respectively.

Total non-elective hospitalizations for ischemic and non-ischemic HF combined increased overall by $26.7 \%$ over the study period. The increase was particularly for non-ischemic HF $(+43.7 \%)$, of which elderly women formed the predominant group.

\subsection{Crude mortality rates}

Crude cumulative 30-day, 1-year and 5-year all-cause mortality rates for all HF patients admitted in 1990-1993 were $12.1 \%, 29.6 \%$, and $62.6 \%$ respectively, and declined to $8.4 \%, 23.8 \%$, and $54.1 \%$ respectively for patients admitted in 1998-2001. Similar improvements in 5-year crude CV mortality were seen in ischemic $(-12.6 \%)$ and non-ischemic $(-10.6 \%)$ HF subgroups (Table 2 ). The average declines in the 5-year crude CV mortality were not significantly different between genders for either form of HF (Table 2).

\subsection{Determinants of 5-year mortality}

Significant determinants of 5-year mortality identified by multivariable Cox regression models, stratified by ischemic and non-ischemic 
Table 1

Baseline characteristics in patients with ischemic and non-ischemic forms of heart failure, stratified by gender and age groups of $<75$ years and $\geq 75$ years.

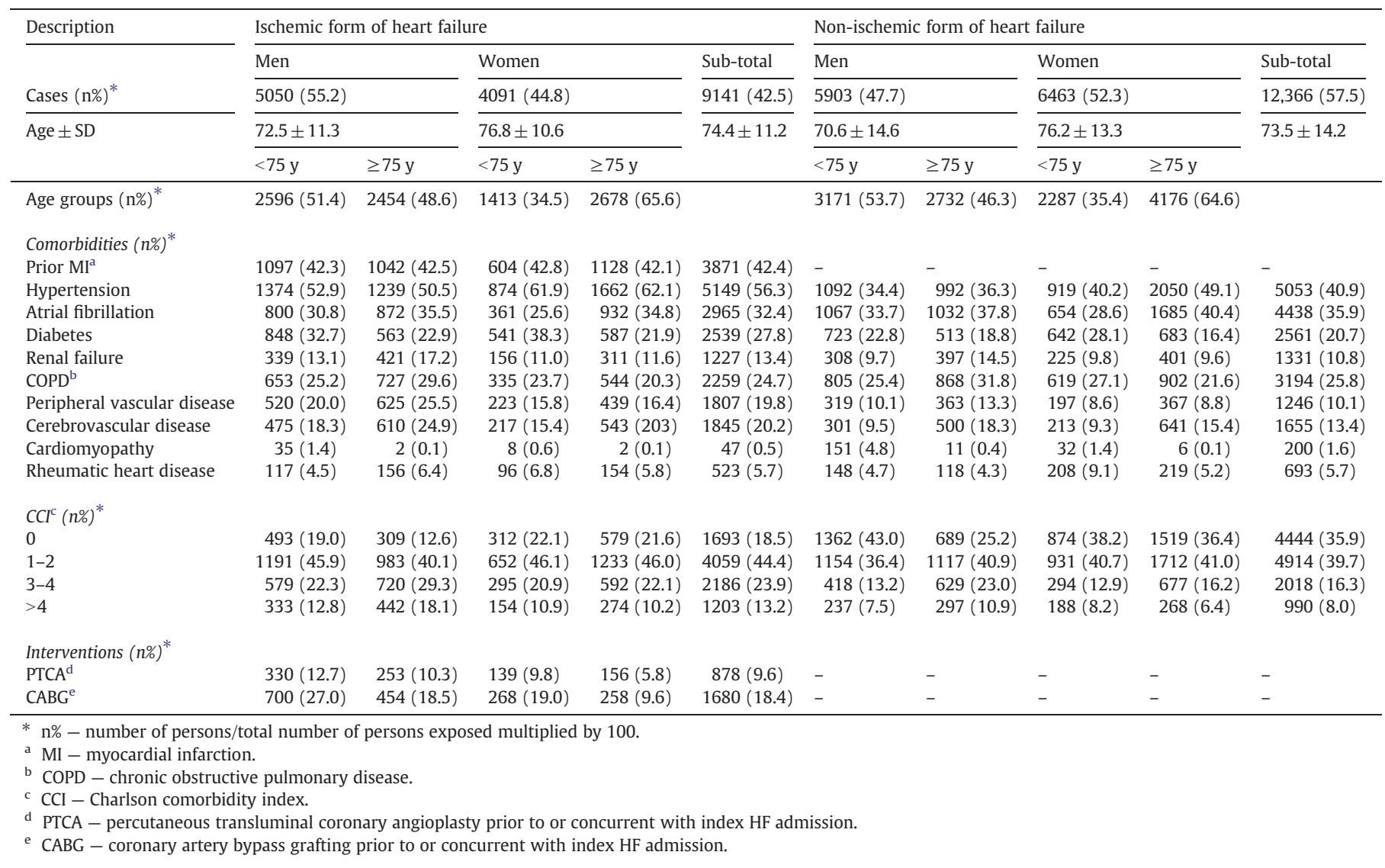

subgroups, included: age group, gender, hospitalization period, CCI, renal failure, hypertension, PVD and cerebrovascular disease. CARPs were significant predictors in the ischemic subgroup only. CARPs performed prior to or concomitant with index HF hospitalization were both significantly associated with lower adjusted hazards of 5-year CV mortality (HR 0.81 and HR 0.64 respectively, both $\mathrm{p} \leq 0.001$ ). Age $\times$ year and sex $\times$ year interaction terms were included in all regression models.

\subsection{Multivariate-adjusted hazard of 5-year mortality}

Compared to 1990-1993, the fully-adjusted 5-year CV mortality declined for the ischemic sub-group with HR 0.72 and 0.65 (both $\mathrm{p}<0.001$ ) for 1994-1997 and 1998-2001, respectively. Similar trends were seen in patients with non-ischemic HF with adjusted HR 0.82 and 0.63 for the same periods (both $\mathrm{p}<0.001$ ).

Gender and age-stratified subgroup analyses found that adjusted 5-year CV mortality also improved over the subsequent periods for both men and women, in those above and below age 75 years, and in patients with ischemic and non-ischemic HF (Tables 3a and 3b, Fig. 1a and b, Fig. 2a and b). Significant annual relative declines in adjusted mortality were demonstrated in all subgroups (Tables 3a and 3b).

\section{Discussion}

The present study investigated long-term CV mortality and morbidity trends in men and women after first hospitalization with ischemic or non-ischemic HF between 1990 and 2005 in WA. We found the age-standardized incidence of index hospitalization for ischemic and non-ischemic HF had both declined substantially, although the decline was relatively modest for women with non-ischemic HF. Importantly, the adjusted 5-year CV mortality after index HF hospital- ization had fallen by around 35\% in both forms of HF, and mortality had improved by a more or less similar extent in both genders and across age groups, However, cumulative 5-year CV mortality was still high $(\approx 40 \%)$ and the overall burden of non-elective hospitalizations for HF increased, particularly for patients with non-ischemic HF.

\subsection{Clinical characteristics of patients with first hospitalization for $\mathrm{HF}$}

The clinical characteristics of our HF cohort were similar to those reported by other population-based studies emanating from other high income countries $[2-4,7,24]$ More than $50 \%$ of our patients were aged $\geq 75$ years with female patients comprising nearly two-thirds of this age group. Hypertension and IHD were the most frequent comorbidities, and although women were less likely to have IHD than men, they still comprised $45 \%$ of patients with ischemic HF.

We had earlier reported that over the study period, index HF cases were increasingly older and had an increasing prevalence of hypertension, AF, diabetes, and renal failure amongst other age-related comorbidities [18]. The adverse trends in serious risk factors of HF are worrying. Specifically, nearly one-quarter of our patients had diabetes, which was more prevalent in those aged $<75$ years. This finding is consistent with the fact that diabetes has emerged as an important precursor to HF in a younger age group [25] and in Australia (like many other countries), the potential pool of middle-aged individuals with obesity and diabetes at risk of developing HF is rising [26].

\subsection{Trend in index HF hospitalizations}

We have found that the age-standardized incidence rate of first HF hospitalization has been steadily decreasing since the 1990s in WA [18] in line with most other countries [6,7]. However the relative 
Table 2

Temporal changes in crude cardiovascular mortality in patients with index HF hospitalization (based on non-elective admissions only) for period, 1990-2001.

\begin{tabular}{|c|c|c|c|c|c|}
\hline $\begin{array}{l}\text { Crude } \\
\text { cardiovascular (CV) } \\
\text { mortality rates }\end{array}$ & $\begin{array}{l}1990-1993 \\
(\alpha)\end{array}$ & 1994-1997 & $\begin{array}{l}1998-2001 \\
(\beta)\end{array}$ & $\begin{array}{l}\text { Percent } \\
\text { change } \\
(\beta-\alpha)\end{array}$ & $\begin{array}{l}\text { P value } \\
\text { for trend }\end{array}$ \\
\hline \multicolumn{6}{|c|}{ Cumulative 30-day CV mortality [n (\%)] } \\
\hline Total cohort & $453(9.1)$ & $366(6.6)$ & $320(5.8)$ & -3.3 & $<0.001$ \\
\hline Ischemic sub-group & $244(11.2)$ & $198(7.7)$ & $163(7.2)$ & -4.0 & $<0.001$ \\
\hline Men & $152(13.5)$ & $108(8.0)$ & $92(7.2)$ & -6.3 & $<0.001$ \\
\hline Women & $92(8.8)$ & $90(7.4)$ & $71(7.3)$ & -1.5 & 0.379 \\
\hline $\begin{array}{l}\text { Non-ischemic } \\
\text { sub-group }\end{array}$ & $209(7.4)$ & $168(5.7)$ & $157(4.9)$ & -2.5 & $<0.001$ \\
\hline Men & $99(7.3)$ & $84(5.8)$ & $71(4.6)$ & -2.7 & 0.008 \\
\hline Women & $110(7.5)$ & $84(5.5)$ & $86(5.1)$ & -2.4 & 0.009 \\
\hline \multicolumn{6}{|c|}{ Cumulative 1-year CV mortality [n (\%)] } \\
\hline Total cohort & $1030(20.7)$ & $897(16.2)$ & $807(14.7)$ & -6.0 & $<0.001$ \\
\hline Ischemic sub-group & $530(24.4)$ & 459 (17.9) & $388(17.2)$ & -7.2 & $<0.001$ \\
\hline Men & $307(27.3)$ & $260(19.2)$ & $232(18.1)$ & -9.2 & $<0.001$ \\
\hline Women & $223(21.3)$ & $199(16.5)$ & $156(16.1)$ & -5.2 & 0.002 \\
\hline $\begin{array}{l}\text { Non-ischemic } \\
\text { sub-group }\end{array}$ & $500(17.8)$ & $438(14.7)$ & $419(13.0)$ & -4.8 & $<0.001$ \\
\hline Men & $246(18.2)$ & $231(15.9)$ & 195 (12.7) & -5.5 & $<0.001$ \\
\hline Women & $254(17.4)$ & $207(13.6)$ & $224(13.2)$ & -4.2 & 0.001 \\
\hline \multicolumn{6}{|c|}{ Cumulative 5-year CV mortality (with 5-year follow-up) [n (\%)] } \\
\hline Total cohort & $2096(42.1)$ & $1958(35.3)$ & $1673(30.5)$ & -11.6 & $<0.001$ \\
\hline $\begin{array}{l}\text { Ischaemic } \\
\text { sub-group }\end{array}$ & $1015(46.8)$ & $964(37.6)$ & $770(34.2)$ & -12.6 & $<0.001$ \\
\hline Men & $548(48.7)$ & 533 (39.3) & 446 (34.7) & -14.0 & $<0.001$ \\
\hline Women & 467 (44.7) & $431(35.6)$ & 324 (33.5) & -11.2 & $<0.001$ \\
\hline $\begin{array}{l}\text { Non-ischemic } \\
\text { sub-group }\end{array}$ & $1081(38.5)$ & $994(33.4)$ & 903 (27.9) & -10.6 & $<0.001$ \\
\hline Men & $517(38.2)$ & $493(34.0)$ & $413(26.8)$ & -11.4 & $<0.001$ \\
\hline Women & $564(38.7)$ & 501 (32.9) & 490 (28.9) & -9.8 & $<0.001$ \\
\hline
\end{tabular}

* Cumulative mortality\% $=$ (total number of deaths/total number of persons exposed) $\times 100$.

decline in incident HF was not uniform across subgroups. In particular, age-standardized incidence of HF declined much less in women with non-ischemic versus ischemic HF ( $-13 \%$ versus $-41 \%$ respectively). It is known that among patients with new-onset HF, nearly 50\% have PSF, and these patients are more likely to be older and female with history of hypertension and AF rather than ischemic HF [16]. This observation is in keeping with the clinical characteristics of our elderly sub-cohort with non-ischemic HF (see Table 1), and the echocardiographic findings in a random sub-sample of our index HF population [17]. An increasing incidence of elderly women who develop predominantly HF with PSF may increase the prevalence of HF in the population over time, as suggested by Owan et al. [27]. Consistent with this we observed a much greater increase in overall hospitalization burden for non-ischemic compared to ischemic HF over the period.

\subsection{Trends in long-term mortality}

We found that the decline in 30-day and 1-year CV mortality after index HF hospitalization in WA between 1990 and 2005 was maintained up to 5 years after hospitalization. Compared to 19901993 , there was $\approx 20 \%$ reduction in adjusted 5 -year mortality for new HF cases admitted in 1994-1997, and $\approx 35 \%$ reduction for cases admitted in 1998-2001. This finding is consistent with the few contemporary population-based studies that have reported long-term time trends in mainly all-cause mortality after HF hospitalization $[3,6,7]$. However, to our knowledge there has only been one other study that compared trends separately in men and women with ischemic and non-ischemic HF [24]. In this Swedish hospital registry study [24], it was reported that long-term (3-year) all-cause mortality for HF decreased more for men than for women and more for ischemic than non-ischemic HF. By contrast, we found that all subgroups of women and men, including the elderly, with ischemic and nonischemic HF had significant improvements in adjusted long-term CV mortality, with only marginal differences in survival gains between subgroups (Tables 3a and 3b, Fig. 1a and b, Fig. 2a and b). While this is encouraging, it is important to note that the prognosis of $\mathrm{HF}$ is still poor with cumulative 5 -year CV mortality of approximately $40 \%$ in our cohort.

The reasons for improvement in survival cannot be ascertained definitively in the present study. The use of ACE-inhibitors became widespread in the early 1990s and subsequently beta-blockers and aldosterone antagonists were used increasingly [8-10,17]. This might explain why much of the long-term survival gain had occurred by the earlier period (1994-1997). Despite this, other studies performed during this period indicate that these prognostic therapies were still under-prescribed (so-called treatment gap) in most countries surveyed including Australia $[7,15,17,28]$. We can only speculate as to the further improvement in outcomes that may be obtained by closing this treatment gap. The use of cardiac resynchronization therapy and implantable cardioverter defibrillators have increased since the last period of our study but would likely have minimal impact on overall survival in the broad HF population.

Also during the same period, ACE-inhibitors, beta-blockers, and statins have been increasingly used in addition to CARPs after AMI leading to an improved long-term survival particularly in those patients at high risk of developing HF [11-13,27]. In this regard we noted an ever-increasing use of CARPs throughout the study period in the ischemic subgroup, and either PTCA or CABG was a strong independent predictor of better long-term survival. By contrast, the

Table 3a

Trends in adjusted five-year cardiovascular mortality following index hospitalization for ischemic heart failure, stratified by gender and age group.

\begin{tabular}{|c|c|c|c|c|c|c|c|c|c|c|c|}
\hline \multirow[t]{2}{*}{ Age group } & \multirow[t]{2}{*}{ Period } & \multicolumn{5}{|c|}{ Five-year CV mortality in men $^{\ddagger}$} & \multicolumn{5}{|c|}{ Five-year CV mortality in women ${ }^{\ddagger}$} \\
\hline & & $\mathrm{N}^{*}$ & Percent $^{\dagger}$ & $\mathrm{HR}$ & $95 \% \mathrm{CI}$ & p-value & $\mathrm{N}^{*}$ & Percent $^{\dagger}$ & $\mathrm{HR}$ & $95 \% \mathrm{CI}$ & p-value \\
\hline \multirow[t]{4}{*}{$<75$ years } & 1990-1993 & 252 & 40.1 & \multicolumn{3}{|c|}{1.00 (baseline) } & 109 & 28.8 & \multicolumn{3}{|c|}{1.00 (baseline) } \\
\hline & 1994-1997 & 219 & 31.2 & 0.73 & $0.60-0.89$ & 0.001 & 93 & 22.2 & 0.69 & $0.51-0.92$ & 0.011 \\
\hline & 1998-2001 & 164 & 25.3 & 0.60 & $0.49-0.74$ & $<0.001$ & 67 & 19.7 & 0.61 & $0.44-0.84$ & 0.002 \\
\hline & & $\begin{array}{l}\text { Mear } \\
\text { year, }\end{array}$ & $\begin{array}{l}\text { ine per } \\
\% \mathrm{Cl})\end{array}$ & $7.1 \%$ & 4.7-9.6 & $<0.001$ & $\begin{array}{l}\text { Mean } \\
\text { year, }\end{array}$ & $\begin{array}{l}\text { ine per } \\
\% \mathrm{CI})\end{array}$ & $5.2 \%$ & $1.4-8.8$ & 0.007 \\
\hline \multirow[t]{4}{*}{$\geq 75$ years } & 1990-1993 & 297 & 59.4 & \multicolumn{3}{|c|}{1.00 (baseline) } & 358 & 53.7 & \multicolumn{3}{|c|}{1.00 (baseline) } \\
\hline & 1994-1997 & 314 & 48.2 & 0.71 & $0.60-0.84$ & $<0.001$ & 338 & 42.7 & 0.71 & $0.61-0.83$ & $<0.001$ \\
\hline & 1998-2001 & 282 & 44.3 & 0.64 & $0.53-0.76$ & $<0.001$ & 257 & 41.1 & 0.71 & $0.60-0.84$ & $<0.001$ \\
\hline & & \multicolumn{2}{|c|}{$\begin{array}{l}\text { Mean decline per } \\
\text { year,\% }(95 \% \mathrm{CI})\end{array}$} & $6.0 \%$ & $3.9-8.1$ & $<0.001$ & \multicolumn{2}{|c|}{$\begin{array}{l}\text { Mean decline per } \\
\text { year,\% }(95 \% \mathrm{CI})\end{array}$} & $4.5 \%$ & $2.5-6.4$ & $<0.001$ \\
\hline
\end{tabular}

* Multivariable Cox regression model adjusted for age, Charlson comorbidity index, renal failure, hypertension, cerebrovascular disease, peripheral vascular disease, diabetes, COPD, AF, history of PTCA, history of CABG, PTCA undertaken with index HF admission and CABG undertaken with index HF admission.

* $\mathrm{n}$ (total number of deaths) within 5 years from time zero (date of index admission for HF).

$\dagger$ Refers to percentage mortality (deaths/number of persons exposed) within 5 years from time zero. 
Table 3b

Trends in adjusted five-year cardiovascular mortality following index hospitalization for non-ischemic heart failure, stratified by gender and age groups.

\begin{tabular}{|c|c|c|c|c|c|c|c|c|c|c|c|}
\hline \multirow[t]{2}{*}{ Age group } & \multirow[t]{2}{*}{ Period } & \multicolumn{5}{|c|}{ Five-year CV mortality in men ${ }^{\S}$} & \multicolumn{5}{|c|}{ Five-year CV mortality in women ${ }^{\S}$} \\
\hline & & $\mathrm{N}^{*}$ & Percent $^{\dagger}$ & $\mathrm{HR}$ & $95 \% \mathrm{CI}$ & p-value & $\mathrm{N}^{*}$ & Percent $^{\dagger}$ & HR & $95 \% \mathrm{CI}$ & p-value \\
\hline \multirow[t]{4}{*}{$<75$ years } & 1990-1993 & 217 & 29.2 & \multicolumn{3}{|c|}{1.00 (baseline) } & 133 & 23.5 & \multicolumn{3}{|c|}{1.00 (baseline) } \\
\hline & 1994-1997 & 198 & 24.6 & 0.82 & $0.67-1.00$ & 0.051 & 92 & 16.5 & 0.66 & $0.50-0.87$ & 0.003 \\
\hline & 1998-2001 & 132 & 16.5 & 0.52 & $0.41-0.65$ & $<0.001$ & 81 & 13.6 & 0.53 & $0.40-0.71$ & $<0.001$ \\
\hline & & \multicolumn{2}{|c|}{$\begin{array}{l}\text { Mean decline per } \\
\text { year,\% }(95 \% \mathrm{CI})\end{array}$} & $7.2 \%$ & $4.8-9.6$ & $<0.001$ & \multicolumn{2}{|c|}{$\begin{array}{l}\text { Mean decline per } \\
\text { year,\% }(95 \% \mathrm{CI})\end{array}$} & $8.6 \%$ & $5.4-11.7$ & $<0.001$ \\
\hline \multirow[t]{4}{*}{$\geq 75$ years } & 1990-1993 & 300 & 49.3 & \multicolumn{3}{|c|}{1.00 (baseline) } & 431 & 48.3 & \multicolumn{3}{|c|}{1.00 (baseline) } \\
\hline & 1994-1997 & 295 & 45.7 & 0.90 & $0.77-1.07$ & 0.237 & 409 & 42.3 & 0.82 & $0.71-0.94$ & 0.004 \\
\hline & 1998-2001 & 281 & 38.1 & 0.69 & $0.59-0.82$ & $<0.001$ & 409 & 37.3 & 0.66 & $0.58-0.76$ & $<0.001$ \\
\hline & & \multicolumn{2}{|c|}{$\begin{array}{l}\text { Mean decline per } \\
\text { year,\% }(95 \% \mathrm{CI})\end{array}$} & $4.1 \%$ & $2.2-6.0$ & $<0.001$ & \multicolumn{2}{|c|}{$\begin{array}{l}\text { Mean decline per } \\
\text { year,\% }(95 \% \mathrm{CI})\end{array}$} & $5.3 \%$ & $3.7-6.9$ & $<0.001$ \\
\hline
\end{tabular}

$\S$ Multivariable Cox regression model adjusted for age, Charlson comorbidity index, renal failure, hypertension, cerebrovascular disease, peripheral vascular disease, diabetes, COPD, AF.

* $\mathrm{n}$ (total number of deaths) within 5 years from time zero (date of index admission for HF).

$\dagger$ Refers to percentage mortality (deaths/number of persons exposed) within 5 years from time zero.

rate of death from HF with PSF is likely to remain unchanged with little or no current evidence-based treatments for this disorder $[14,16]$.

\section{Limitations}

In the present study the diagnosis of HF was obtained from an administrative database without further internal validation. However, we have previously shown that a principal diagnosis of HF in the WA
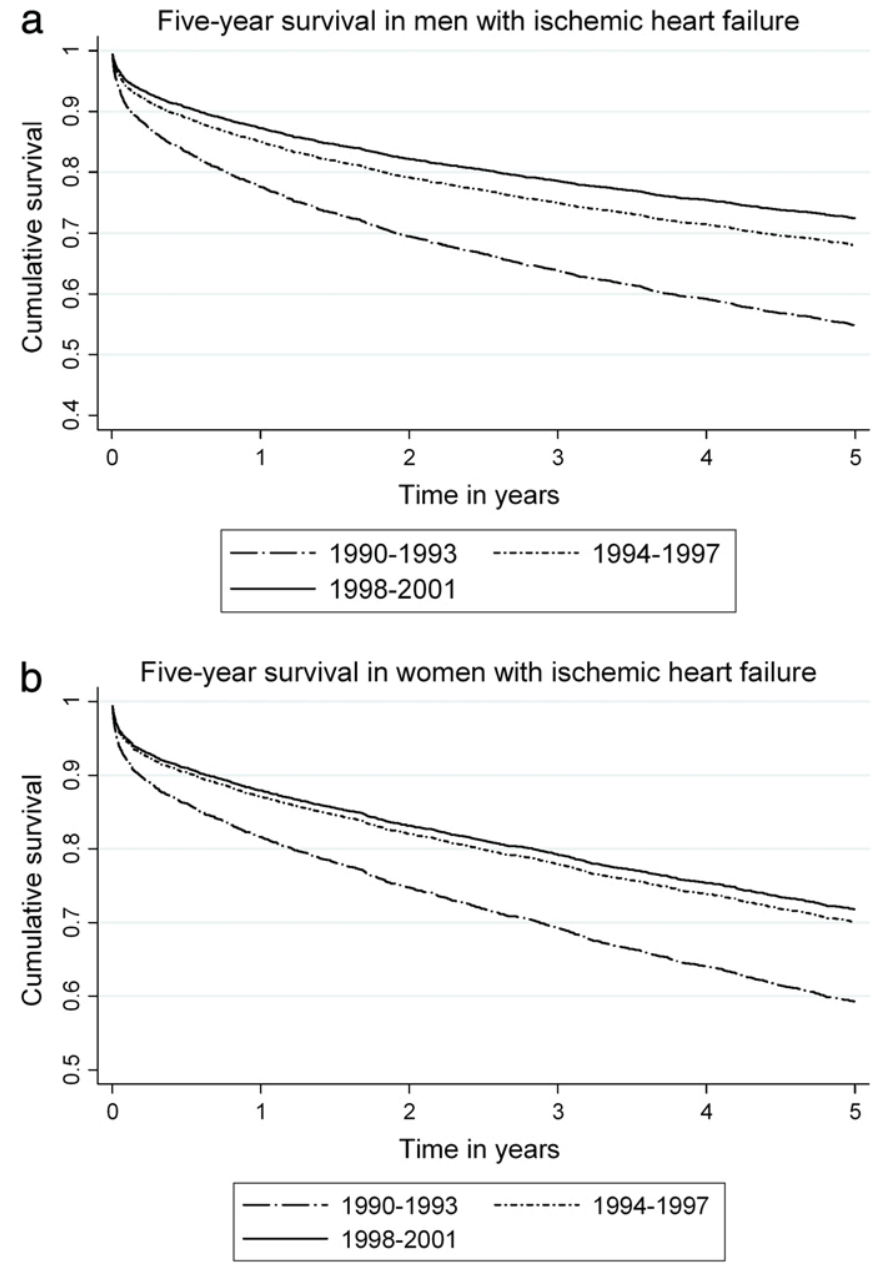

Fig. 1. Five-year survival of men and women (with ischemic heart failure) admitted with a first heart failure hospitalization for years 1990-2001, comparing three time intervals: 1990-1993 (as baseline, long dash dotted line); 1994-1997 (short dash dotted line); 7 and 1998-2001 (continuous line).
HMD has a high positive predictive accuracy [20]. Temporal changes in coding practices and in diagnostic accuracy may have affected the information on comorbidities and their trends, although there is a high accuracy for coding of interventional procedures [29]. We had no information about left ventricular function, prescribed medication, or long-term clinical management for patients, except in a random subsample [17]. Consequently we are unable to ascertain the association of these factors with trends in survival.
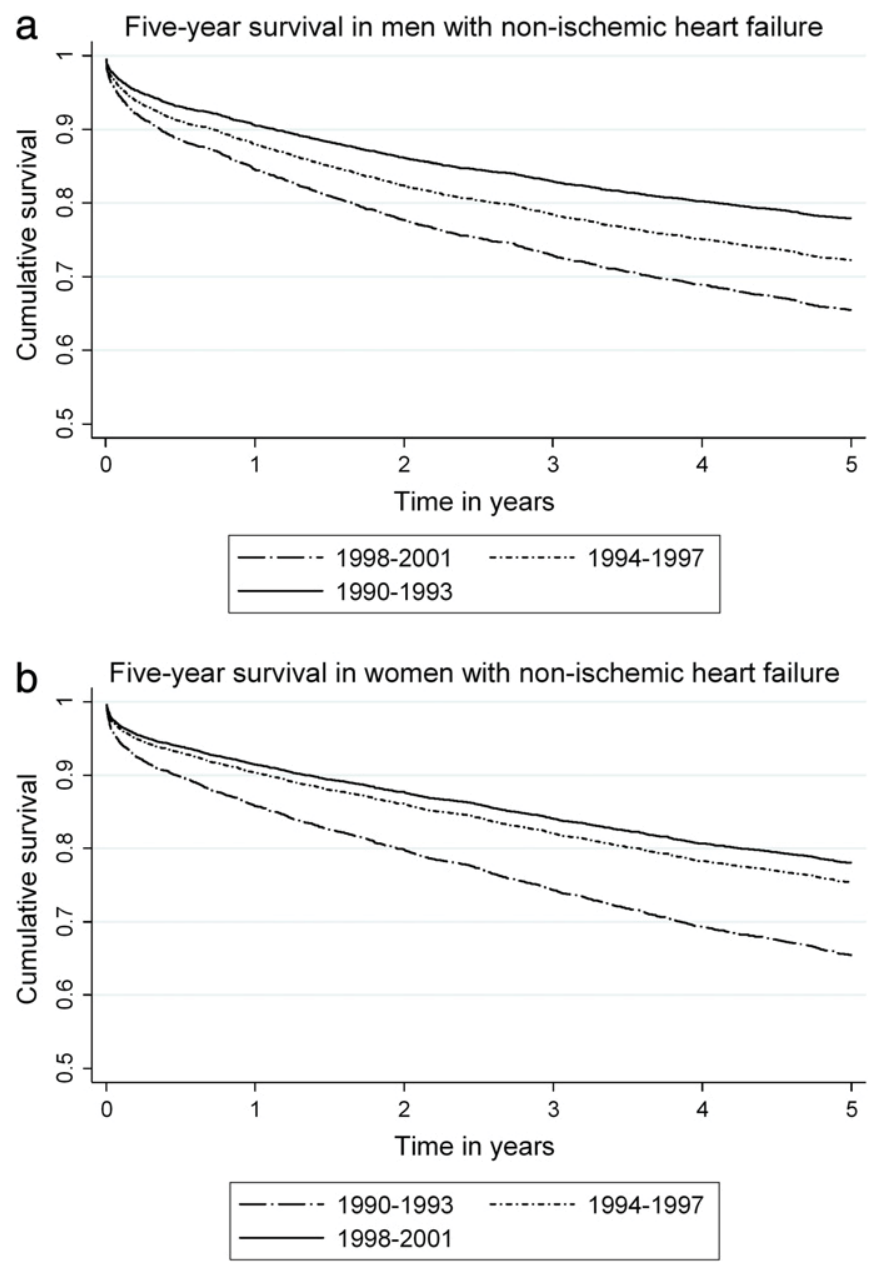

Fig. 2. Five-year survival of men and women (with non-ischemic heart failure) admitted with a first heart failure hospitalization for years 1990-2001, comparing three time intervals: 1990-1993 (as baseline, long dash dotted line); 1994-1997 (short dash dotted line); and 1998-2001 (continuous line). 


\section{Conclusions}

Long-term survival for HF has significantly improved for patients with ischemic and non-ischemic HF, and in both women and men across age groups, during the contemporary era of HF management in Western Australia. Although incident hospitalization rates for HF have fallen overall, the declines are not uniform across heterogeneous subgroups and the burden of hospitalizations for non-ischemic HF has increased substantially over the recent period. These trends and the persistent poor prognosis of HF patients underscore the need for more effective strategies for detection and treatment of HF, especially in those with PSF.

\section{Acknowledgements}

This study has been supported by an award (NHF G08P 3675) from the National Heart Foundation of Australia. Simon Stewart is supported by the National Health and Medical Research Council of Australia. The authors thank the Data Linkage Branch, Department of Health WA, for the providing the linked data.

The authors of this manuscript have certified that they comply with the Principles of Ethical Publishing in the International Journal of Cardiology [30].

\section{References}

[1] Rosamond W, Flegal K, Friday G, et al. Heart disease and stroke statistics - 2007 update: a report from the American Heart Association Statistics Committee and Stroke Statistics Subcommittee. Circulation 2007;115:e69-e171.

[2] MacIntyre K, Capewell S, Stewart S, et al. Evidence of improving prognosis in heart failure: trends in case fatality in 66547 patients hospitalized between 1986 and 1995. Circulation 2000;102:1126-31.

[3] Levy D, Kenchaiah S, Larson MG, et al. Long-term trends in the incidence of and survival with heart failure. N Engl J Med 2002;347:1397-402.

[4] Roger VL, Weston SA, Redfield MM, et al. Trends in heart failure incidence and survival in a community-based population. JAMA 2004;292:344-50.

[5] Goldberg RJ, Ciampa J, Lessard D, Meyer TE, Spencer FA. Long-term survival after heart failure: a contemporary population-based perspective. Arch Intern Med 2007;167:490-6.

[6] Stewart S, Ekman I, Ekman T, Oden A, Rosengren A. Population impact of heart failure and the most common forms of cancer. A study of 1162309 hospital cases in Sweden (1988-2004). Circ Cardiovasc Oual Outcomes 2010;3:573-80.

[7] Jhund PS, Macintyre K, Simpson CR, et al. Long-term trends in first hospitalization for heart failure and subsequent survival between 1986 and 2003: a population study of 5.1 million people. Circulation 2009;119:515-23.

[8] Garg R, Yusuf S. Overview of randomized trials of angiotensin-converting enzyme inhibitors on mortality and morbidity in patients with heart failure. Collaborative Group on ACE Inhibitor Trials. JAMA 1995;273:1450-6.

[9] McMurray JJ. Major beta blocker mortality trials in chronic heart failure: a critical review. Heart 1999;82(Suppl 4):IV14-22.

[10] Pitt B, Zannad F, Remme WJ, et al. The effect of spironolactone on morbidity and mortality in patients with severe heart failure. Randomized Aldactone Evaluation Study Investigators. N Engl J Med 1999;341:709-17.
[11] Steg PG, Kerner A, Van de Werf F, et al. Impact of in-hospital revascularization on survival in patients with non-ST-elevation acute coronary syndrome and congestive heart failure. Circulation 2008;118:1163-71.

[12] Briffa T, Hickling S, Knuiman M, et al. Long term survival after evidence based treatment of acute myocardial infarction and revascularisation: follow-up of population based Perth MONICA cohort, 1984-2005. BMJ 2009;338:b36.

[13] Setoguchi S, Glynn RJ, Avorn J, Mittleman MA, Levin R, Winkelmayer WC. Improvements in long-term mortality after myocardial infarction and increased use of cardiovascular drugs after discharge: a 10-year trend analysis. J Am Coll Cardiol 2008;51:1247-54

[14] Hogg K, Swedberg K, McMurray J. Heart failure with preserved left ventricular systolic function; epidemiology, clinical characteristics, and prognosis. J Am Coll Cardiol 2004;43:317-27.

[15] Galvao M, Kalman J, DeMarco T, et al. Gender differences in in-hospital management and outcomes in patients with decompensated heart failure: analysis from the Acute Decompensated Heart Failure National Registry (ADHERE). J Card Fail 2006;12:100-7.

[16] Bhatia RS, Tu JV, Lee DS, et al. Outcome of heart failure with preserved ejection fraction in a population-based study. N Engl J Med 2006;355:260-9.

[17] Teng T-H, Hung J, Finn J. The effect of evidence-based medication use on long-term survival in patients hospitalized for heart failure in Western Australia. MJA 2010;192:306-10.

[18] Teng T-H, Finn J, Hobbs M, Hung J. Heart failure: incidence, case-fatality and hospitalization rates in Western Australia between 1990 and 2005. Circ Heart Fail 2010;3:236-43.

[19] Holman CD, Bass AJ, Rouse IL, Hobbs MS. Population-based linkage of health records in Western Australia: development of a health services research linked database. Aus NZ J Public Health 1999;23:453-9.

[20] Teng T-H, Finn J, Hung J, Geelhoed E, Hobbs M. A validation study: how effective is the hospital morbidity data as a surveillance tool for heart failure in Western Australia? Aus NZ J Public Health 2008;32:405-7.

[21] Charlson ME, Pompei P, Ales KL, MacKenzie CR. A new method of classifying prognostic comorbidity in longitudinal studies: development and validation. J Chronic Dis 1987:40:373-83.

[22] Australian Bureau of Statistics. Causes of Death, Australia, 2008; 2010 [cited 3 December 2010]; Available from: http://www.abs.gov.au/ausstats/abs@.nsf/mf/3303.0/.

[23] Australian Bureau of Statistics. Population by Age and Sex, Australian States and Territories; 2008 [cited 2008 April 25]; 3201.0:[Electronic product]. Available from: http://www.abs.gov.au/AUSSTATS/abs@.nsf/MF/3201.0.

[24] Shafazand M, Schaufelberger M, Lappas G, Swedberg K, Rosengren A. Survival trends in men and women with heart failure of ischaemic and non-ischaemic origin: data for the period 1987-2003 from the Swedish Hospital Discharge Registry. Eur Heart J 2009;30:671-8.

[25] Nichols GA, Gullion CM, Koro CE, Ephross SA, Brown JB. The incidence of congestive heart failure in type 2 diabetes: an update. Diab Care 2004;27:1879-84.

[26] Cameron AJ, Dunstan DW, Owen N, et al. Health and mortality consequences of abdominal obesity: evidence from the AusDiab study. Med J Aust 2009;191:202-8.

[27] Owan TE, Hodge DO, Herges RM, Jacobsen SJ, Roger VL, Redfield MM. Trends in prevalence and outcome of heart failure with preserved ejection fraction. N Engl J Med 2006;355:251-9.

[28] Masoudi FA, Rathore SS, Wang Y, et al. National patterns of use and effectiveness of angiotensin-converting enzyme inhibitors in older patients with heart failure and left ventricular systolic dysfunction. Circulation 2004;110:724-31.

[29] Hobbs MS, McCaul KA, Knuiman MW, Rankin JM, Gilfillan I. Trends in coronary artery revascularisation procedures in Western Australia, 1980-2001. Heart 2004;90:1036-41.

[30] Shewan LG and Coats AJ. Ethics in the authorship and publishing of scientific articles Int J Cardiol 2010;144:1-2. 